\title{
EDUCACIÓN SEXUAL INTEGRAL E INFANCIA: CUESTIONES PLANTEADAS EN ESTUDIOS BRASILEÑOS EN EL CONTEXTO DEL CARIBE LATINO
}

\author{
COMPREHENSIVE SEXUAL EDUCATION AND CHILDHOOD: ISSUES RAISED IN \\ BRAZILIAN STUDIES WITHIN THE LATIN CARIBBEAN CONTEXT
} EDUCAÇÃO SEXUAL INTEGRAL E INFÂNCIA: PROBLEMÁTICAS LEVANTADAS AOS
ESTUDOS BRASILEIROS NO INTERIOR DO CONTEXTO LATINO-CARIBENHO

\section{Claudionor Renato da Silva ${ }^{1}$}

Fecha de recepción: 01-04-2021

Fecha de aceptación y versión final: 27-07-2021

\section{Resumen}

La Educación Sexual Integral (ESI) no es un término recurrente en los estudios en el área de Educación Sexual en Brasil. En la motivación que da la propuesta RIIE, este estudio problematiza la ESI en Educación Infantil en territorio brasileño, tratando de comprender por qué la terminología / concepto / metodología (políticas, acciones educativas) no está presente en las producciones nacionales. Los argumentos que orientan las respuestas a la problematización se encuentran en el rescate histórico del extinto RCNEI, de la década de 1990, que puede considerarse una política de ESI. Como guía, la investigación postula que una de las formas de reflexión sobre la "problemática" de los estudios brasileños es pensar en los fundamentos de la Educación Integral como las primeras acciones en el contexto de América Latina y el Caribe ( $\mathrm{AL}$ y $\mathrm{Ca}$ ), sobre Educación Infantil. El estudio concluye con la defensa de un mayor diálogo / alianza de investigadores brasileños con investigadores de centros de investigación en LA y CA, que incluye la coordinación activa con movimientos sociales y partidos políticos, desde las ciudades brasileñas al ámbito estatal y federal en el sentido de formular políticas públicas en ESI en Educación Infantil.

Palabras clave: América Latina y el Caribe - Educación infantil brasileña - Educación sexual integral - Infancia.

\begin{abstract}
Comprehensive Sexual Education (CSE) is not a recurring term within current studies in the area of Sexual Education in Brazil. In terms of the RIIE proposal's initiative, this essay-based study problematizes CSE in Brazilian Early Childhood Education; in the first place, by trying to understand why the terminology/ conceptualization/methodology (education policies and actions) are absent in national productions. The argumentative answers to the problematization are found in the historical rescue of the extinct RCNEI of the 1990s, which can be considered a CSE policy. As a guideline, this paper postulates that one of the ways of reflecting upon the "problematization" of Brazilian studies is to think about the foundations of Comprehensive Education as one of the first actions on Childhood Education within the context of Latin America and the Caribbean (LA and $\mathrm{Ca}$ ). The study concludes by advocating for a greater dialogue/partnership of Brazilian researchers with researchers of research centers in LA and the $\mathrm{Ca}$, including the active coordination with social movements and political parties from Brazilian cities to the State and the federal levels, so as to formulate public policies on CSE in Early Childhood Education.
\end{abstract}

\footnotetext{
${ }^{1}$ Universidade Federal de Jataí, Brasil. Correo electrónico: rclaudionor@ufj.edu.br Revista del Instituto de Investigaciones en Educación ISSN $1853-1393$

Resistencia, Chaco. Argentina
} 
Key words: Latin America and the Caribbean - Brazilian Early Childhood Education Comprehensive Sexual Education - Childhood.

\section{Resumo}

Educação Sexual Integral (ESI) não é um termo recorrente nos estudos da área da Educação Sexual no Brasil. Na motivação dada pela proposta da RIIE, o presente estudo de caráter ensaístico, problematiza a ESI na Educação Infantil em território brasileiro, primeiro, procurando compreender o porquê que a terminologia/conceito/metodologia (políticas, ações educativas) não está presente nas produções nacionais. Os argumentos que guiam as respostas à problematização estão no resgate histórico dos extintos RCNEI, da década de 1990 que pode ser considerado uma política de ESI. Como encaminhamento, a investigação postula que um dos caminhos de reflexão das "problemáticas" dos estudos brasileiros estejam em pensar as bases da Educação Integral como primeiras ações no interior do contexto da América Latina e Caribe (AL e Ca), sobre a Educação Infantil. Conclui-se o estudo com a defesa por um maior diálogo/parceria de pesquisadores (as) brasileiros(as) com pesquisadores(as) de centros de pesquisa da $\mathrm{AL}$ e $\mathrm{Ca}$, o que inclui coordenações ativas com os movimentos sociais e partidos políticos, das cidades brasileiras para a esferas estadual e federal no sentido de formulação de políticas públicas em ESI na Educação Infantil.

Palavras-chave: América Latina e Caribe - Educação Infantil brasileira - Educação Sexual Integral - Infância. 


\section{Introdução}

Educação Sexual Integral (ESI) no Brasil é um termo não muito utilizado nos estudos em Educação Sexual, muito menos nas temáticas referentes à sexualidade infantil ou a sexualidade e gênero na Educação Infantil, tão pouco nas políticas educacionais mais recentes. Contudo, pode-se pontuar que nos anos 1990 houve ESI na Educação Infantil nos extintos Referenciais Curriculares Nacionais para a Educação Infantil - RCNEI (Brasil, 1998).

As pesquisas sobre Educação Sexual parecem se concentrar mais nos aspectos educativos deixando os aspectos de saúde e de cuidados em outro corpus discursivo e de pesquisa o que configuraria uma ESI.

$\mathrm{Na}$ tentativa de alinhamento e problematizações em torno dos aspectos terminológico/conceitual/metodológico às produções sobre a ESI no âmbito da América Latina, o que inclui, obviamente, o Brasil, tem-se, neste trabalho, sobretudo, o parâmetro da UNESCO (2000; 2010), a Lei N. 26.150/2006 da Educação Sexual Integral na Argentina, incluindo as Leis $26.485 / 2009$, sobre a violência contra as mulheres e a Lei n.27.234/2015 que trata da violência de gênero e a educação para a igualdade. E no Uruguai, com discussões que se desdobram desde os anos 1920, a Lei Geral de Educação n. 18.437/2008, que confere ao currículo escolar, o enfoque em Educação Sexual.

Somam-se algumas produções como os de Lamas (1996), Darré (2005), Benedet e Gómez (2015), Faur, Gogna e Binstock (2015), Gonzalez (2017), escritos que se projetam na presente problematização, qual seja, a ESI nas produções brasileiras, com enfoque na Educação Infantil. Especial destaque à obra coordenada por Marina Mirta (Argentina, 2009) que trata diretamente da ESI na escola primária. Uma amplitude ou abrangência para uma totalidade ou próximo à esta totalidade das produções latino-americanas e caribenhas, exigiriam mais tempo e espaço de pesquisa, contudo, esses trabalhos aqui elencados, permitem um breve diálogo com as produções oficiais aqui em destaque que, no entender da pesquisa, ajudam na compreensão da problemática exposta, já que existe uma ampla produção sobre o tema, mas que não é foco deste estudo um estado da arte, mas a pontuação de uma problemática a partir, especialmente, de documentos oficiais.

Mas, quais as problemáticas centrais da pesquisa, apresentadas já no título do artigo? São elas: 1) por que o Brasil não possui uma política explícita de Educação Sexual, de Educação Sexual Integral voltada à educação básica, em especial à Educação Infantil, do mesmo modo, por que as produções sobre a ESI e a ESI na Educação Infantil não fazem parte do nosso arcabouço de pesquisas? 2) Por que ainda são ínfimas a terminologia, o conceito e a metodologia em ESI na América Latina e Caribe, sobretudo, nos documentos oficiais da ONU, da OMS (Organização Mundial da Saúde) e das próprias legislações de alguns países que estão à frente em políticas explícitas de ESI?

Dialogar com a prática e a política da ESI no Brasil para a Educação Infantil, problematizando-a e, também, invocando aos pesquisadores (as) a se articularem à problemática do estudo. Entender o desenvolvimento da ESI nos demais países da América Latina podem suscitar práticas e políticas, formações e informações necessárias, no âmbito das pesquisas e também dos movimentos sociais com propostas às instituições que recebem crianças, meninos e meninas em todas as 
cidades brasileiras, visto que a Educação Infantil está sob a governabilidade dos municípios.

De metodologia bibliográfica com base em Sampieri, Collado e Lúcio (2006) o estudo inicia com o levantamento de pesquisas brasileiras - portanto, em Língua Portuguesa - que procuraram tratar o tema, em uma rápida busca no Google Acadêmico, de 2017 para cá, incluindo citações.

Os critérios de inclusão é que os artigos em periódicos apresentem a palavra "integral" ao lado de Educação Sexual. Logo, exigiu-se uma leitura dos Resumos e do próprio corpus dos textos para inclusão no elencamento da pesquisa. Foram mais de cinquenta artigos pesquisados, alguns lidos na íntegra para se identificar sob o descritor "Educação Sexual Integral", produções que tratassem o tema na Educação Infantil.

Chama a atenção os estudos sobre a temática, sobretudo para o Brasil, em diálogos com a América Latina, visto que, em tempos de pandemia, segundo Ferreira et al. (2020), a OMS recomendou que as ações de Educação Sexual Integral fossem redobradas, sob uma base nos Direitos Humanos e serviços de saúde e cuidado às crianças pequenas. E a pergunta que nos cabe, enquanto pesquisadores é: não havendo sequer um currículo em Educação Sexual no Brasil que atenda o mínimo da educação em sexualidade, o que se faz ou que se discutir em termos de saúde e em termos de integralidade da sexualidade em tempos de isolamento social em que as crianças estão sendo cuidadas por pais ou responsáveis, irmãos mais velhos, em situações de extrema vulnerabilidade? O que estamos deixando escapar de nossa atividade de pesquisas e militância pró infância na formulação de políticas que atendam à obrigatoriedade de uma ESI?

O tema nos instiga a problematizar e iniciar diálogos entre a comunidade de pesquisadores brasileiros (as) e diálogos em parceria com pesquisadores(as) da América Latina e Caribe, para serem pensadas nesse momento de pandemia e póspandemia uma ESI com discursos articulados e ações efetivas na macrorregião.

\section{A quase ausência da ESI na produção brasileira}

O máximo que se chega nas produções brasileiras, levantadas por meio da pesquisa bibliográfica em Sampieri. Collado e Lúcio (2006), em coleta realizada para trabalhos no período de 2017 para cá, é uma rápida menção da ESI que não chega a ser uma definição terminológica, como no artigo, a seguir.

Uma proposta de Educação Sexual integral não deve se limitar às questões biológicas, mas sim considerar os fatores sociais e históricos que constroem a sexualidade que vivemos. O conhecimento sobre o corpo humano, práticas sexuais, reprodução etc. é fundamental, mas somado a ela é preciso refletir sobre a construção cultural dos valores e representações associadas. (Moreira, Maia \& Jacinto, 2020, p. 53)

O levantamento, em sua totalidade, permite a identificação de que "integral" é tomado como sinônimo de dimensões da sexualidade que se totalizam ou que se completam, para além do saber reprodutivo, por exemplo, nos currículos do ensino de ciências. 
Não há, em nenhum momento dos artigos levantados, uma referência, seja à UNESCO, seja em trabalhos de referencial teórico sobre a ESI ou a ESI na infância, uma epistemologia mínima, ou indicação de políticas locais, por exemplo, de criação de uma política de ESI na Educação Infantil.

Moreira, Maia e Jacinto (2020) apresentam a Educação Sexual como Educação Integral, mas apenas numa forma de citação aberta sem aprofundamentos ou referenciais. Esse artigo é o mais próximo à ESI que se encontrou no levantamento e nenhum trabalho sobre a ESI na Educação Infantil.

Isso leva a compreender, a princípio, que para a Educação Sexual no Brasil, o "integral" basta às discussões de currículo, de sala de aula e de formações iniciais em cursos ou oficinas, nas universidades. O "integral" em sexualidade, nas produções em Educação Sexual, apenas está aproximada à saúde e, praticamente, não temos, na atualidade, depois dos extintos RCNEI e PCN (Parâmetros Curriculares Nacionais), absolutamente nada em termos de políticas em Educação Sexual, a não ser as Diretrizes de 2013 (Brasil, 2013), em que nas Diretrizes em Direitos Humanos se "autoriza" falar de algumas temáticas de gênero, mas voltadas, à violência, quase que em sua totalidade, como apontou Silva (2017).

O que o levantamento das produções em periódicos brasileiros demonstrou é que o termo ESI é quase desconhecido e não utilizado nas últimas produções, desde 2017. Há apenas algumas aproximações.

Há um estudo que fala de Educação Sexual e Educação Integral (Mendes \& Araújo, 2017), contudo, separadamente. $\mathrm{Na}$ entrevista com professores, o estudo revelou que a Educação Sexual não alcança status de componente curricular e muitas das posições dos professores (as) são de resistência. Agora, a associação à Educação de Tempo Integral (ETI) alcança maior proximidade de entendimento por parte dos professores, colocando-a como critério para a qualidade da educação na educação básica.

Silva e Lionço (2019) apenas fazem menção à Lei argentina de 2006 sobre ESI e o Programa de ESI, em 2008. Atestam que, nesse país, diferentemente, do Brasil, há um foco educacional mais atuante no palco legislativo, enquanto que por aqui, as forças religiosas, sobretudo, acabam por "controlar" decisões legislativas, acima da educação, acima da saúde, acima dos valores cidadãos democráticos, liberais e laicos. No Brasil, não temos uma Lei que defina direitos de aprendizagem sobre a sexualidade humana. A nossa Lei de Diretrizes e Bases é omissa quanto à sexualidade e a Educação Sexual, apesar dos RCNEl e os PCN dos anos 1990, agora, extintos pela BNCC (Base Nacional Comum Curricular) que se tornou ainda mais omisso.

Viçosa et al. (2020) ao investigar junto a adolescentes sobre seus conhecimentos em Educação Sexual, afirmam ser a escola, principal foco de seus conhecimentos, mais gerais, e atrelam à Educação Sexual, a saúde. O texto traz principais leis na Argentina e Uruguai, que versam sobre a ESI e as questões relativas à saúde reprodutiva e a violência contra mulheres nos terrenos legais.

Há menção de "saúde integral" no artigo de Vieira, Matsukura e Vieira (2017), confirmando a hipótese inicial da Introdução em que a Educação Sexual parece não "abrigar", nos estudos brasileiros, a questão da saúde. 
As pautas políticas mais amplas do que se poderia configurar como ESI no Brasil estão, na verdade, no campo da saúde, iniciando-se com o foco nos adolescentes, voltando-se à questão da gravidez na adolescência, doenças transmissíveis, etc. No destaque de estudos nessa vertente está o Caderno de Atenção Básica sobre a Saúde Sexual e Reprodutiva de Adolescentes e Jovens (BRASIL, 2013) que é recorrente no levantamento. Tudo que se trata de "integral" na produção está atrelado à saúde: 1) nunca voltado à criança pequena; 2) foco nos adolescentes e a ideia de doenças transmissíveis ou gravidez na adolescência.

Esse movimento de "ausência" da ESI no Brasil e, particularmente, sua ausência nos últimos anos, nas produções em artigos e na total inexistência de uma ESI na primeira infância leva-nos a alguns alertas, mesmo que haja uma vasta produção sobre Educação Sexual na Educação Infantil. Mas, do ponto de vista desta problematização, Educação Sexual na infância, Educação Sexual na Educação Infantil, Educação Sexual na formação de professores em Pedagogia, e toda e qualquer sentença ou categoria que possa ser criada, não configura ESI, tal como a consideraremos nesse artigo, seguindo a UNESCO e a produção de países da América Latina e Caribe que assumiram que suas instituições seriam configuradas num currículo de Educação Sexual. A Educação Sexual Integral é, antes de tudo, uma política pública ampla, que autoriza um currículo em sexualidade humana.

Para autores(as)/pesquisadores(as) da Educação Sexual brasileira, a sexualidade é parte integral ao humano. Mas, essa aplicação do "integral" parece muito simplória. Ela não atende a dimensão da ESI tal como está construída nos documentos da UNESCO sobre sexualidade humana, Educação Sexual, nem nos documentos dos países que resolveram assumir a Educação Sexual nos currículos escolares, desde a infância.

Desse ponto de vista, será que a problematização a ser feita sobre a ESI no Brasil, passa pela consideração de que Educação Sexual já é integral em si, sem a necessidade de ser ESI, em termos terminológicos, conceituais e metodológicos, problematizações desse estudo, para o caso brasileiro?

Na próxima seção será evidenciado a ESI em sua aplicação na educação infantil em obras que apontam a terminologia, o conceito e as práticas, tanto políticas quanto metodológicas, para instituições e docentes, ou seja, a "legislação" maior que estabelece, institui a prática da ESI nas escolas; são documentos oficiais que começam pela UNESCO.

\section{A construção terminológica, conceitual e metodológica para a ESI a partir das produções da América Latina e Caribe}

Nesta seção se procura saber se há uma construção terminológica, conceitual e metodológica sobre a ESI na Educação Infantil na América Latina e Caribe, com base nas produções da UNESCO, em articulação direta à Organização Mundial da Saúde, as experiências da Argentina na promulgação da ESI e outras políticas de gênero e sexualidade (Argentina, 2009, 2005, 2019), e a Lei Geral de Educação do Uruguai. (Uruguay, 2008).

A UNESCO, desde os anos 2000, vem constituindo Comitês para discutir políticas em sexualidade humana, desde a primeira infância, para toda América Latina e Caribe. 
Em UNESCO (2010), Ministros da Saúde e da Educação da América Latina e Caribe no documento UNESCO (2010, p.11) anunciaram um comprometimento com a Educação Sexual Integral, no entendimento de que "[...] abarca aspectos éticos, biológicos, afectivos, sociales, culturales y de género, así como de derechos humanos; el respeto por la diversidad de las orientaciones e identidades sexuales".

Embora, não seja uma definição terminológica, nem um conceito, expressa a política ou noção democrática e compromisso dos estados-membros com a ESI que entendiam, naquele momento, que não se faz ESI sem políticas de Estado ou "estratégias" multissetoriais. Políticas de Estado que o Brasil não possui e que todas as possibilidades de uma mínima discussão ou potencial ESI foram totalmente eliminadas com o fim dos RCNEI na Educação Infantil e os PCN no Ensino Fundamental e, junto a isso, as forças conservadoras da política nacional, também contribuíram para esse impacto.

O "integral" parece encontrar ecos numa ideia ou noção de que a Educação Sexual se faz por ação de vários setores do estado, por exemplo, a educação, a saúde, a assistência social, a segurança pública. Uma segunda observação: as dimensões da Educação Sexual Integral e multissetorial convergem para uma proposta na tarefa social das instituições que recebem as crianças pequenas. Pelo menos, essa tem sido a estratégia das produções da UNESCO ao longo dos anos 2000, porém com uma atenção à adolescência, mas sem deixar de lado as preocupações com a infância.

Mas todas essas postulações da UNESCO culminam em ações para o currículo sem se deter ao aspecto terminológico e conceitual. Parece haver um apressamento em "fazer" do que conceber instrumentos epistemológicos do que seria, de fato, "Educação Sexual Integral". Essa questão inicial abrange um segundo tópico na problemática aqui construída para o tema da pesquisa. Talvez, precisamos de uma epistemologia mais consolidada, menos "apressada" que operacionalize na América Latina e Caribe, uma ESI para a infância, seguindo o fluxo de nossa reflexão e pesquisa.

A ESI na Argentina e a Lei Geral de Educação uruguaia que são destaques nas produções sobre o tema da ESI na América Latina e Caribe, por possuírem políticas explícitas em Educação Sexual no currículo escolar, serão os enfoques analíticos a seguir.

$\mathrm{Na}$ Lei que cria, em 2006, o Programa de Educação Sexual Integral na Argentina (Argentina, 2006), a ESI é entendida como "direito"; apoia-se nas decisões para a América Latina e Caribe, contra a violência contra crianças, mulheres, e proteção de direitos de crianças e adolescentes; compromisso com as relações de gênero, nos espaços escolares.

O artigo 9 prevê uma interação com pais ou responsáveis, com formação e informação em Educação Sexual nas instituições escolares

a) Ampliar la información sobre aspectos biológicos, fisiológicos, genéticos, psicológicos, éticos, jurídicos y pedagógicos en relación con la sexualidad de niños, niñas y adolescentes;

b) Promover la comprensión y el acompañamiento en la maduración afectiva del niño, niña y adolescente ayudándolo a formar su sexualidad y preparándolo para entablar relaciones interpersonales positivas; 
c) Vincular más estrechamente la escuela y la familia para el logro de los objetivos del programa. (Argentina, 2006)

Esse aspecto formativo na unidade escolar é muito positivo para o construto terminológico, conceitual e metodológico em ESI para a Educação Infantil. Não se pode pensar uma Educação Sexual séria, apenas na relação professor-aluno e nas "ocorrências" do dia a dia nas relações crianças-crianças é preciso que seja uma política de Estado. A lei de 2006 e todas as demais legislações posteriores, na Argentina, trazem contribuições à problematização que se está elaborando nesse artigo e que, para o Brasil, demonstram muitos avanços que, apesar de toda a produção nacional, alcançada hoje em território brasileiro, há um distanciamento muito grande do ideário da ESI para a América Latina e Caribe.

No documento oficial do Ministério da Educação da Nação Argentina (Argentina, 2009), coordenado por Marina Mirta apresenta-nos os Lineamientos Curriculares para la Educación Sexual Integral (ESI) (p. 5) marcados por experiências em ESI, que resultaram num "acordo" sobre práticas curriculares para a educação, como política pública educacional.

Marina Mirta, nesta obra ao Ministério da Educação, demonstra que a ESI começa com o entendimento do termo: sexualidade. E, quando os estudos na América Latina e Caribe começaram a debater os direitos da infância e da criança, a dimensão da sexualidade não podia mais ser colocada de lado, tanto pela escola, os pais e os próprios sistemas de ensino da macrorregião.

Sexualidade, portanto, não está ligado ao órgão genital, nem a relação sexual, entre duas pessoas, mas, são construções da pessoa humana, dimensões psíquicas, estéticas, sociais, afetivas, éticas - nas bases da OMS e UNESCO.

Educação Sexual Integral no documento oficial Argentina (2009) possui a seguinte concepção:

En las instituciones educativas, la Educación Sexual Integral constituye un espacio sistemático de enseñanza y aprendizaje que comprende contenidos de distintas áreas curriculares, adecuados a las edades de niños y niñas, y abordados de manera transversal y/o en espacios específicos. Incluye el desarrollo de saberes y habilidades para el cuidado del propio cuerpo; la valoración de las emociones y de los sentimientos en las relaciones interpersonales; el fomento de valores y actitudes relacionados con el amor, la solidaridad, el respeto por la vida y la integridad de las personas; y el ejercicio de los derechos relacionados con la sexualidad. También promueve el trabajo articulado con las familias, los centros de salud y las organizaciones sociales. Asumir la educación sexual desde una perspectiva integral demanda un trabajo dirigido a promover aprendizajes desde el punto de vista cognitivo, pero también en el plano de lo afectivo, y en las prácticas concretas vinculadas a la vida en sociedad. (Argentina, 2009, p. 6)

Essa citação ainda não dá à ESI um status de epistemologia, mas um passo inicial para esse propósito. Também indica alguns itens a serem seguidos numa proposta de ESI: ocorre nas instituições escolares; constitui-se em processos de ensino-aprendizagem transversais e em espaços específicos (em áreas do conhecimento específicas - interdisciplinaridades); está relacionado a direitos, direitos 
à conhecer e a saber sobre sexo, sexualidade; para além dos espaços da escola, articulação às famílias, unidades de saúde e movimentos sociais; são aspectos que envolvem o cognitivo (o saber; formação e informação científica em sexualidade humana), o afetivo (relacionar-se com o outro e os outros) e as práticas (vivências sociais saudáveis e de liberdade; tomadas de decisões; habilidades psicossociais em relação a sexualidade, a diversidade sexual, etc.) em sociedade, em espaços sociais amplos.

Essas contribuições terminológicas, conceituais e metodológicas, reitera-se que ainda não são epistemê; são apresentadas sem um referencial teórico. São construções partir da Lei de ESI argentina. Junto com a UNESCO há um início de problematização para um construto epistemológico para a ESI para a América Latina e Caribe.

Uruguai (2008) apresenta a educação sexual como tema transversal no currículo, diretamente na sua Lei Geral de Educação. Está como uma linha transversal diferente dos direitos humanos, bem como, da educação científica.

Isso permite uma elaboração embrionária de uma perspectiva epistemológica para a ESI, para a América Latina e Caribe, ao lado das ponderações conceituais em Argentina (2009) e UNESCO (2010).

No seu conjunto essas ponderações dão ao Brasil e aos estudos brasileiros em Educação Sexual um alerta bem simples, já que não temos uma política de Educação Sexual nacional: a educação sexual é uma linha de atuação epistemológica independente no seu corpus, o que não é a mesma coisa que dizer que não é interdisciplinar, multidisciplinar. Desta forma não há como "misturá-la" com direitos humanos, ensino de ciências, etc., pois, compromete a linguagem (em Educação Sexual), não evidencia as questões inerentes à sexualidade humana e gera um "aglomerado" de discussões que, embora, possam ser (e estão) interligadas, precisam de uma assistência epistêmica, histórica, estética, cultural, antropológica, de saúde pública e, fundamentalmente, curricular.

Novamente, o caráter prático, sem a problemática terminológica e conceitual (epistêmica) se vê presente também nesse documento legal uruguaio, especificamente no Artigo 40 item 8:

8) La educación sexual tendrá como propósito proporcionar instrumentos adecuados que promuevan en educadores y educandos, la reflexión crítica ante las relaciones de género y la sexualidad en general para un disfrute responsable de la misma. (Uruguay, 2008)

Todos os documentos/obras oficiais aqui comentados, exceto Argentina (2009) que faz um esforço inicial de terminologia, conceito e metodologia, todos os demais não apresentam uma teorização específica, ainda que mínima sobre ESI; partem sempre de uma metodologia, no sentido de práticas que o Estado assume, institui e que a escola deve cumprir.

Entende-se, assim, que em relação à terminologia, conceito e metodologias, que envolvem as práticas que advém de políticas e as próprias práticas em si, muito bem desenvolvidas em alguns países da América Latina e Caribe, que faltam subsídios terminológico-conceituais ou de epistemologias sobre ESI e ESI na infância. Logo, uma problemática para os estudos brasileiros e, agora, uma problemática para toda a macrorregião latino-americana e caribenha: organização de uma epistemologia 
em ESI. Sem ela seguimos em nossas metodologias? Sim. Precisamos de uma epistemologia mais segura? Talvez não, mas seu uso terminológico conceitual seria uma base interessante para países, como o Brasil, que não possuem nenhuma política explícita de educação sexual, consiga resinificar a continuidade de suas produções num alinhamento continental, intelectual e de políticas públicas articuladas.

Segue-se na problematização aos estudos brasileiros em ESI na Educação Infantil apresentando um breve histórico de um espaço-tempo muito rico para a educação brasileira, o final dos anos 1990, quando havia uma deliberação curricular para a Educação Infantil que evidenciava a sexualidade humana para meninos e meninas atendidos nas creches e escolas de educação infantil, em tempo integral.

\section{Possibilidades de problematização por uma ESI na Educação Infantil brasileira: os extintos RCNEI e o debate em torno da Educação Integral}

Como continuidades da problematização há aqui uma "provocação", para o desenvolvimento de pesquisas em potencial no Brasil em ESI na Educação Infantil, alinhando-se à produção na América Latina e Caribe, de forma a serem potencializadores de políticas públicas locais de Educação Sexual.

Na particularidade da Educação Infantil brasileira, pode-se considerar que já houve um projeto de currículo em Educação Sexual Integral, pós anos 1980, com os Referenciais Curriculares Nacionais da Educação Infantil, os RCNEI (1998), em três volumes.

O resgate rápido da $\mathrm{RCNEI}$ contrasta-se com os retrocessos que a Educação Sexual vem assistindo desde 2014 ou um pouco antes, com os surgimento de leis como os da escola sem partido e a "cartilha-discurso" da ideologia de gênero e que ganharam força, em 2018 e continuam ecoando com fake News gerando ainda mais resistências de escolas e gestores que têm impedido e negado pesquisas em Educação Sexual aos pesquisadores (as) brasileiros (as).

Se pode dizer que os extintos RCNEI (Brasil, 1998) foram efetivamente uma política, um referencial pedagógico de ESI na Educação Infantil. À época, diferentemente de hoje, as práticas em sexualidade sugeridas no documento e praticadas nas escolas que atendiam o dia todo, meninos e meninas, não causaram o impacto resistente e "odioso" assistido, desde 2014, quando as discussões e decisões estavam voltadas para o novo PNE que se iniciaria nesse mesmo ano, 2014, com vigência até 2024.

O que os RCNEI traziam, em especial, no seu primeiro e segundo volumes, num total de três, era uma explícita estrutura curricular que caracterizaria o que estamos a chamar, hoje, de ESI na Educação Infantil, em que as instituições de educação infantil lidariam também e inclusive com a sexualidade dos bebês e das crianças pequenas. Eram instruções diretas, abertas sobre sexualidade e que hoje foram totalmente apagadas da Educação Brasileira, diante da atual BNCC somados aos discursos "anti Educação Sexual" de governos locais e federal, resistindo qualquer tipo ou tentativa de Educação Sexual, seja pelas práticas da área da saúde, seja pelas práticas da área da Educação.

Um importante documento, ainda anterior aos extintos Referenciais Curriculares Nacionais da Educação Infantil (RCNEI) é republicado em 2009, 
elaborado pelo Ministério da Educação do Brasil (Brasil, 2009) - a primeira publicação é de 1995 - e traz importantes critérios de Educação Sexual em creches. Apesar do cuidado do uso, ou melhor, ao evitar o uso das palavras sexualidade, Educação Sexual, mantiveram algumas conquistas dos extintos RCNEI, sob as seguintes palavras-chave: direitos; direitos das crianças na creche. A atual BNCC fala de direitos à aprendizagem também. Brasil (2009) pontua vários direitos das crianças que as creches devem atender. Aqui serão apresentados alguns desses direitos que permitem uma aplicação direta da ESI na Educação Infantil:

\section{Quadro 1}

Alguns critérios de atendimento em creches no Brasil (BRASIL, 2009)

\begin{tabular}{|c|}
\hline DIREITOS A... \\
\hline um ambiente aconchegante, seguro e estimulante \\
\hline higiene e saúde \\
\hline .. desenvolver sua curiosidade, imaginação e capacidade de expressão \\
\hline .. proteção, afeto e amizade \\
\hline ... expressar seus sentimentos \\
\hline $\begin{array}{l}\text {... as meninas também participam de jogos que desenvolvem os movimentos } \\
\text { amplos: correr, jogar, pular }\end{array}$ \\
\hline ... procuramos não deixar as perguntas das crianças sem resposta \\
\hline ... não reprimimos a curiosidade das crianças pelo seu corpo \\
\hline ... não reprimimos a curiosidade sexual das crianças \\
\hline $\begin{array}{l}\text {... ajudamos as crianças a desenvolver seu auto- controle e aprender a lidar com } \\
\text { limites para seus impulsos e desejos }\end{array}$ \\
\hline $\begin{array}{l}\text {... nunca deixamos de procurar entender e tomar providências quando nossas } \\
\text { crianças aparecem na creche machucadas e amedrontadas }\end{array}$ \\
\hline $\begin{array}{l}\text {... procuramos ensinar meninos e meninas como expressar e lidar com seus } \\
\text { sentimentos e impulsos }\end{array}$ \\
\hline $\begin{array}{l}\text {... o bem-estar físico e psicológico das crianças é um de nossos objetivos } \\
\text { principais }\end{array}$ \\
\hline $\begin{array}{l}\text {... a manifestação de preconceitos de raça, sexo ou religião nos mobiliza para } \\
\text { motivar atitudes e comportamentos igualitários na creche }\end{array}$ \\
\hline
\end{tabular}

Fonte: elaboração própria.

Esses são apenas alguns critérios constantes nesse documento, Brasil (2009); outros documentos posteriores a esse, como Brasil (2013), especificamente, as Diretrizes Nacionais para a Educação Infantil, permitem perceber alguns dos mesmos contornos e respaldos dos extintos RCNEI, de modo a ser possível caracterizar essas diretrizes/orientações como uma ESI na Educação Infantil brasileira, mesmo que a BNCC não faça sequer uma única menção a esse documento, tão pouco, uma única menção à Educação Sexual e à sexualidade.

Atualmente, as demarcações políticas e sociais da segunda década dos anos 2000 são desenhos de retrocessos que colocam à pesquisa e às políticas públicas desafios de retomada da base discursiva presente na América Latina sobre a ESI, com enfoque na Educação Infantil. 
Com a extinção dos RCNEI dos anos 1990, substituídos primeiro, pelas Diretrizes Nacionais para a Educação Infantil, de 2019 e republicada em 2013 e, atualmente, pela BNCC, ambas, na sequência, não trazem apontamentos à sexualidade, nem os menciona, nem os exemplifica, a não ser alguns apontamentos nas Diretrizes de Direitos Humanos (Silva, 2017), logo, cabe passarmos à consideração sobre a Educação Integral (Artigo 34 da Lei de Diretrizes e Bases da Educação Nacional), uma aposta às pesquisas na área da Educação Sexual brasileira, com enfoques na Educação Infantil, numa aplicação da terminologia/conceito/metodologia da ESI alinhadas às políticas e ações latinoamericanas e caribenhas.

A problematização terminológica, conceitual e metodológica repousa agora, sobre a Educação Integral como suporte para pensar a ESI na Educação Infantil. Acredita-se que esta escolha seja um caminho para problematizações aos estudos brasileiros quanto ao espaço-tempo-lugar para a ESI; está contemplada na meta 6 do nosso atual Plano Nacional de Educação que se finda em 2024 (PNE, Lei Federal № 13.005/2014).

A Educação Integral é, atualmente, um assunto muito presente na produção brasileira que já vem, desde os anos 1980. Mas, já na década de 1950 já era um projeto nacional, retomado pelos CIEPS, nos anos 1980, no Rio de Janeiro. (Coelho, 2009; Cavalieri e Coelho, 2017; Carneiro e Monteiro, 2020).

Há uma dificuldade em encontrar estudos que relacionem a Educação Integral, a Escola em Tempo Integral, com a dimensão da sexualidade, a partir de uma pergunta simples: há lugar na Educação Integral brasileira para a presença curricular da Educação Sexual, particularmente, na Educação Infantil, de modo que possamos admitir a Educação Integral como uma oportunidade de Educação Sexual Integral?

A resposta ainda é impossível de ser dada completamente, exige uma pesquisa mais aprofundada e um pouco mais de tempo. Mas não deixa de ser uma proposta que se encaixa nas "problemáticas" apresentadas neste ensaio.

Num breve levantamento bibliográfico, no Google Acadêmico, utilizando o demarcador composto: "educação integral; sexualidade" os resultados levam a estudos sobre cuidado integral, ligado à saúde e não à educação integral como política e currículo obrigatório para a escola; prevalece uma associação à educação em saúde e educação médica. Então, procura-se nos estudos da educação integral, a escola em tempo integral se o "integral" inclui também os processos de ensino-aprendizagem em Educação Sexual.

A definição de Carneiro (2015) para a Educação Integral é uma educação que não fica na sala de aula, envolve, dentre outras coisas: " [...], cursos de saúde e bemestar, higiene, nutrição, sexualidade, [...] direitos humanos [...]. (p. 411, grifos meus).

Outra definição de Educação Integral colocada por Gonçalves (2006), já de início, nos coloca em desafiador pensamento sobre a inexistência da Educação Sexual nesses projetos e nesses imensos estudos sobre Educação Integral. A definição:

O conceito mais tradicional encontrado para a definição de educação integral é aquele que considera 0 sujeito em sua condição multidimensional, não apenas na sua dimensão cognitiva, como também 
na compreensão de um sujeito que é sujeito corpóreo, tem afetos e está inserido num contexto de relações. Isso vale dizer a compreensão de um sujeito que deve ser considerado em sua dimensão bio-psicossocial. Acrescentamos, ainda, que o sujeito multidimensional é um sujeito desejante, o que significa considerar que, além da satisfação de suas necessidades básicas, ele tem demandas simbólicas, busca satisfação nas suas diversas formulações de realização, tanto nas atividades de criação quanto na obtenção de prazer nas mais variadas formas. (Gonçalves, 2006, p. 130, grifos meus).

A Educação Integral não teria nada a ver com Educação Sexual Integral, a partir dessas duas rápidas e simples citações? Proporia outra pergunta: o que há de errado com nossas pesquisas sobre Educação Sexual no Brasil e possível alinhamento às políticas, discursos e ações com a ESI na América Latina e Caribe?

Permitam outra questão: que crianças-sujeitos são essas da Educação Integral em que a dimensão da sexualidade, sua sexualidade, não é identificada nas produções sobre essa política/lei da nossa LDBEN? Onde estão esses sujeitos, meninos e meninas, nas instituições da infância em cada município brasileiro?

O que estaria faltando na construção de parâmetros da Educação Sexual para maiores aproximações à ESI, pela Educação Integral, tanto para a Educação Infantil, quanto para os Anos Iniciais é a dimensão do cuidado e da saúde das crianças pequenas e se retirar a "falácia quase sinônima" que Educação Integral é "ficar na escola o dia todo" e que a mesma significa Escola de Tempo Integral, pois estar na escola o dia todo não implica qualidade de ensino e não quer dizer que os temas da Educação Sexual estarão ali - e, aliás, os estudos bibliográficos, indicam que não estão.

Mas, há muito mais a problematizar. Se acredita que essa ponderações iniciais, já bastam para um "alerta" para pesquisadores (as) brasileirosc(as) no tocante a investigações sobre a Educação Integral, já que está perdido os RCNEI e os PCN: promover pesquisas que se impulsionem e "saltem" para políticas públicas, num movimento de legislações em ESI dos municípios para o federal.

Entende-se, assim, que os caminhos reflexivos sobre as "problemáticas" são muito sérias e urgentes ao Brasil: de um lado, um projeto de ESI na Educação Infantil que ficou apenas em obras obsoletas do Ministério da Educação, de outro, uma política de educação integral que se torna um discurso acumulativo, com total ausência da Educação Sexual, como uma dimensão humana negada, silenciada.

Resta, portanto, um alavancamento de pesquisas em território nacional sobre a ESI e a ESI na Educação Infantil a partir de parcerias com centros de pesquisa da América Latina e Caribe. Essa, uma condição urgente aos estudos brasileiros, diante da atual pandemia e que se faz mais urgente no breve processo pós-pandemia, com as vacinas. Se deve iniciar esse "alavancamento" com estudos epistemológicos, teorizações sólidas do que vem a ser ESI alinhando essa teorização aos estudos existentes e em processo, ao mesmo tempo, em que práticas políticas e de formulação de leis se iniciem nas câmaras municipais, para movimentos mais amplos dos espaços federais, o Ministério da Educação brasileiro. A história parece demonstrar que o caminho para discussões da Educação Sexual no Brasil não parece refletir impactos positivos, quando saem dos espaços maiores (da federação) para os 
espaços menores. Nesse sentido, os movimentos sociais, as pesquisas, as experiências das pequenas cidades, expandidas para regiões, talvez, consigam, nesta ação de resistência alcançar um efeito inverso do silenciamento e repressão vivenciados na última edição das discussões nacionais do atual PNE que se finda em 2024.

\section{Sem a intenção de concluir... Mas, manter a problematização...}

Seguem alguns tópicos de ideias ainda bem soltas, como contributos à pesquisa brasileira em Educação Sexual, mas também à pesquisa sobre a ESI na América Latina e Caribe, com foco aos meninos e meninas, atendidos (as) na Educação Infantil, na consideração de toda a diversidade cultural e antropológica da macrorregião.

Tópicos mais gerais:

- A ESI é uma política de estado, é política pública governamental, é um compromisso dos governos em instituir educação sexual no currículo escolar, com impactos à formação de professores nas universidades, em projetos de currículo conhecido de pais e responsáveis, desde a Educação Infantil. O que converge para mudanças nas estruturas sociais patriarcais, violentas à crianças, mulheres e LGBT, estruturas sociais de heranças europeias colonialistas e escravocratas.

- A ESI necessita de uma epistemologia mais densa, ao mesmo tempo aprofundada, horizontal (pesquisas e extensão universitárias, práticas de movimentos sociais e partidos políticos) e verticalmente (leis), para discussões antropológicas em sexualidade para a América Latina e Caribe; as publicações existentes ainda são ínfimas no que diz respeito à epistemologia sobre o tema.

Tópicos mais específicos.

- A pesquisa brasileira em Educação Sexual precisa construir articulações mais efetivas com a saúde, ao mesmo tempo, defender o elaborar de políticas que se tornem efetivas sob a ESI; a fragmentação entre educação e saúde precisa ser paulatinamente ressignificadas para um alinhamento às políticas e às discussões, e ações em ESI no restante da América Latina e Caribe. Há necessidade que a Educação Infantil brasileira estabeleça parcerias com estas Unidades de Saúde em projetos conjuntos que propiciem políticas públicas locais que se expandam para políticas mais amplas, ao nível do estado até chegar à Federação, mesmo, porque, as escolas de educação infantil estão sob os cuidados dos municípios. Os Projetos Pedagógicos das Unidades Escolares podem ser primeiros passos dessas iniciativas.

- Parcerias entre centros de pesquisa em Educação Infantil brasileiros com centros de pesquisa da América Latina e Caribe que, sobretudo, já possuam uma "estrada" em ESI. Essa parceria evidenciaria a construção terminológica, conceitual e metodológica em ESI, com alinhamentos que vão de uma epistemologia do "lugar" às práticas do dia a dia de professores (as), desde a formação universitária inicial, em licenciaturas, por meio de disciplinas específicas de ESI, oficinas pedagógicas, estágios e práticas de ensino. 
- Torna-se urgente para os estudos brasileiros em Educação Sexual Integral na Educação Infantil o entendimento da sexualidade infantil no contexto da pandemia, com as crianças em suas casas, o fator do abuso e da violência sexual. E o pensar para o retorno gradual, quando do formato presencial, com as vacinas, como lidar com as "perdas" do isolamento social, os desgastes emocionais e traumas infantis, etc. Sugere-se a política da Educação Integral, como um potencial motor de práticas e políticas locais em ESI.

Tanto os tópicos mais amplos e gerais como os específicos são muito desafiadores à América Latina e Caribe, bem como, e muito mais, ao Brasil que não possui uma política de compromisso com a Educação Sexual. Esses tópicos são ideia em fermentação intelectual a serem desenvolvidas em território brasileiro pelo NuEPFES - Núcleo de Estudos, Pesquisas e Formação em Educação Sexual, na Universidade Federal de Jataí.

De toda forma, as problematizações que se colocam nesse artigo é um movimento de diálogo entre pesquisadores (as) brasileiros(as) da Educação Sexual e da Educação Infantil em discutirem teórica e metodologicamente uma ESI, uma ESI que se torne políticas públicas. Uma proposta que está muito distante de acontecer, de se efetivar, mas, as práticas já desenvolvidas no Brasil, nossas pesquisas são, talvez, o motor dessa proposta aqui desenvolvida. São iniciativas simples de olhar o que temos e estabelecer as parcerias entre centros de pesquisa da educação sexual e da educação infantil, formando redes na América Latina e Caribe, para o estabelecimento da ESI.

Acredita-se, ser um plano em longa prazo, diante do cenário de nossas pesquisas atuais no Brasil e a situação política nacional. Mas, a parceria e diálogo entre pesquisas e pesquisadores da América Latina e Caribe pode ser um desses primeiros caminhos de se pensarem as problematizações aqui expostas, que podem se transformar em políticas públicas locais, nas cidades brasileiras, visando a integralidade do desenvolvimento e do direito à aprendizagem sobre sexualidade humana de meninos e meninas.

Aproveitem as ideias "soltas" nestes tópicos, caso sejam úteis e estabeleçamos diálogos, parcerias de produção e reflexão na irremediável e urgente tarefa acadêmica e militante, sobretudo, para o Brasil, em promover Educação Sexual Integral às crianças, às meninas e meninos, no interior do contexto da ESI na América Latina e Caribe.

\section{Referencias bibliográficas}

Argentina. (2009). Educación sexual integral para la edcución primaria: contenidos y propuestas para el aula. Buenos Aires. Ministerio de Educación de la Nación.

Argentina. (2019). Presidencia de la Nación, Cultura, Ciencia y Tecnología. Ministerio de Educación. Secretaría de Evaluación Educativa. Educación sexual integral en la escuela primaria. Voces de estudiantes, docentes y directivos en Aprender 2018. Buenos Aires: Secretaría de Evaluación Educativa.

Argentina. (2005). Ley no 26.061, del 2005. Protección integral de los derechos de niñas, niños y adolescentes. Boletín Oficial de la República Argentina. Buenos Aires. 
Benedet, L. y Gómez, A. (2015). La educación sexual en Uruguay: enfoques en disputa en la genealogía de la política pública. Temas de Educación, 21 (1), 11-30. Recuperado https://revistas.userena.cl/index.php/teduacion/article/view/653

Darré, S. (2005). Políticas de género y discurso pedagógico. Uruguay: Ediciones Trilce.

Brasil. (2013). Ministério da Saúde. Saúde Sexual e Reprodutiva de adolescentes e jovens - Caderno de Atenção Básica, Brasília.

Brasil. (2009). Ministério da Educação. Critérios para um Atendimento em Creches que respeite os Direitos Fundamentais das crianças. 6. ${ }^{a}$ ed. Brasília: Ministério da Educação.

Carneiro, M.A. (2015). LDB Fácil. Leitura crítico-compreensiva artigo a artigo. Petrópolis, RJ: Vozes.

Carneiro, W., y Monteiro, S. (2020). Ensaio sobre educação integral: análise de experiências e apontamentos conceituais. Brazilian Journal of Development, 6 (6), p. 38627-38639. Recuperado de https://www.brazilianjournals.com/index.php/BRJD/article/view/11849

Coelho, L. M., y C. Costa (org.). (2009). Educação integral em tempo integral: estudos e experiências em processo. Rio de Janeiro: FAPERJ.

Cavalieri, S.M.V. y Coelho. L. M.C (orgs.). (2017). Pesquisas sobre educação integral e tempo integral: história, políticas e práticas. Curitiba: CRV, 2017.

Faur, E.; Gogna, M. y Binstock, G. (2015). La Educación Sexual Integral en la Argentina balances e desafíos de la implementación da ley (2008-2015). Buenos Aires: Ministerio de Educación.

Ferreira, V., Silva, M. R. F., Mantovani, E. H., Colares, L. G., Ribeiro, A. A. y Stofel, N. S. (2020). Saúde da mulher, gênero, políticas públicas e Educação Médica: agravos no contexto de pandemia. Revista Brasileira de Educação Médica, 44 (1),1-8. doi https://doi.org/10.1590/1981-5271v44.supl.1-20200402

Gonçalves, A. S. (2006). Reflexões sobre educação integral e escola de tempo integral. Cadernos CENPEC. 2, 129-135. Recuperado de http://cadernos.cenpec.org.br/cadernos/index.php/cadernos/article/view/136

Gonzalez, B. M. (2017). Orientação sexual nas escolas: análise dos dizeres dos documentos oficiais do Brasil e da Argentina. Dissertação MestradoUniversidade Federal de Uberlândia, Programa de Pós-Graduação em Estudos Linguísticos. Recuperado de http://repositorio.ufu.br/handle/123456789/21281.

Lamas, M. (1996). El género: La construcción cultural de la diferencia sexual. México: Grupo Editorial Miguel Ángel Porrúa-P.U.E.G.

Mendes, H. C., y Araújo, L. F. (2017). Representações sociais da sexualidade e da educação integral: um estudo entre professores da rede pública de ensino. Revista Educação e Emancipação, 10 (1), 191-207. Recuperado de http://www.periodicoseletronicos.ufma.br/index.php/reducacaoemancipacao/ar ticle/view/6977

Moreira, M. C., Maia, A. C. B., y Jacinto, H. F. A. (2020). Educação Sexual nas escolas: concepções e práticas de professores. Revista Psicologia e Educação On-Line, 3 (1), 47-54, 2020. Recuperado de: http://psicologiaeeducacao.ubi.pt/Files/Other/Artigos\%20OnLine/2020V1/V3N $1 \% 20-\% 205 . p d f$

OMS. (2020). Organización Mundial del Salud. Comisión Interamericana de Derechos Humanos. Pandemia y derechos humanos en las Américas. Recuperado de https://www.oas.org/es/cidh/decisiones/pdf/Resolucion-1-20-es.pdf 
Silva, C. G., y Lionço, T. (2019). Temas perigosos para a educação? Juventudes, instituições de ensino, gênero e sexualidade. Inter-Ação, .44 (1),180-195, Recuperado de https://www.revistas.ufg.br/interacao/article/view/48959/33081

Silva, C.R. (2017). Educação Sexual a partir das Diretrizes Curriculares em Direitos Humanos: feminilidades e masculinidades em discussão. Sodebrás, 12, p.6872. Recuperado de http://www.sodebras.com.br/edicoes/N137.pdf

Uruguay. (2008). Ley no 18.437, del 2008. Ley General de Educación. Diario Oficial de la República Oriental del Uruguay. Montevideo. Recuperado de https://www.impo.com.uy/bases/leyes/18437-2008

Viçosa, C.S.C.L. y Santana, E.B., Viçosa, D.L., Lima, C.E., D’Andrea. A.M., Salgueiro, A.C.F. y Folmer, V. (2020). Saúde adolescente e Educação Sexual na escoa: tessituras a partir das perspectivas dos estudantes. Research, Society and Development, 9 (6), 1-27. doi http://dx.doi.org/10.33448/rsd-v9i6.3613

Vieira, P. M., Matsukura, T.S. y Vieira, C.M. (2017). Políticas públicas e Educação Sexual: percepções de profissionais da saúde e da educação. INTERtheis, 14 (3), 69-87. doi 10.5007/1807-1384.2017v14n3p69 